\title{
Identification of the bacterial composition in the rockworm gut and biofloc-fed adult gut flora beneficial for integrated multitrophic aquaculture
}

\author{
Hyun Yi Jung', Chang Hoon Kim², Joong Kyun Kim ${ }^{1, *}$ \\ ${ }^{1}$ Department of Biotechnology, Pukyong National University, Busan 48513, Korea \\ ${ }^{2}$ Department of Marine Bio-Materials and Aquaculture, Pukyong National University, Busan 48513, Korea
}

\begin{abstract}
The rockworm gut flora was identified at each growth stage to elucidate the composition of the bacterial community. The source material was Marphysa sanguinea fed regular feed and fed biofloc at the adult stage in parallel. The systematic bacterial community composition was determined based on the next-generation sequencing method, and alpha diversity and beta diversity were conducted to access the species diversity within and between the bacterial communities, respectively. The composition of the gut flora changed considerably as the rockworms developed. The shift in the gut flora was confirmed at the phylum, family, and genera level of the bacterial communities. The Vibrio species associated with high rockworm mortality occupied $7.7 \%$ of the gut flora at the larval stage; however, they disappeared in the healthy adult gut. Moreover, different gut flora was observed between adults fed regular feed and those fed biofloc. Specifically in the biofloc-fed adult gut, several immune relevant and water-purifying bacteria were detected. The biofloc-fed adult gut flora could decompose and mineralize organic sediment, and thus be effectively utilized for integrated multitrophic aquaculture. The Venn diagram revealed that only two bacterial species were shared throughout all growth stages, and the biofloc-fed adults exhibited the highest diversity within the bacterial community.
\end{abstract}

Keywords: Rockworm gut, Bacterial composition, Biofloc, Biofloc-fed adults, Integrated multitrophic aquaculture

\section{Introduction}

Rockworm is a filter feeding animal that exhibits low food intake during the larval stages, which increases during the juvenile stages. Bacterial communities in the earthworm gut have been reported to change when earthworms are fed on diverse substrates (Aira et al., 2016). Based on these findings, a gradual change in the rockworm gut flora is presumed at the juvenile stage. Moreover, the gut flora has been known to play an important role in the immune system, influencing the rockworm life cycle (McFall-Ngai et al., 2013). Rockworms, including Marphysa sanguinea, Perinereis aibuhitensis, P. nuntia, and

Received: Jul 7, 2021 Revised: Aug 3, 2021 Accepted: Aug 8, 2021

${ }^{*}$ Corresponding author: Joong Kyun Kim

Department of Biotechnology, Pukyong National University, Busan 48513, Korea

Tel: +82-51-629-5866, Fax: +82-51-629-5863, E-mail: junekim@pknu.ac.kr

This is an Open Access article distributed under the terms of the Creative Commons Attribution Non-Commercial License (http://creativecommons.org/licenses/by$\mathrm{nc} / 4.0 /$ ) which permits unrestricted non-commercial use, distribution, and reproduction in any medium, provided the original work is properly cited.

Copyright $\odot 2021$ The Korean Society of Fisheries and Aquatic Science 
Nectoneanthes oxypoda have been used domestically as live bait for fishing. Rockworms are also an important nutrient source for stimulating gonad maturation and spawn in both fish and crustaceans for hatching. The natural production of rockworms is associated with some limitations due to their poor tolerance at low temperatures (Prevedelli, 1994), and populations have decreased due to excessive hunting since the 1980s. Therefore, the demand for rockworms has rapidly been increased in recent years (especially for $M$. sanguinea) for the purpose of aquaculture production and the development of related technology.

Polychaetes are involved in purifying deposits by changing organic ingredients through their feeding behavior, thereby mitigating the potential for environmental impact. The effects of microorganisms derived from polychaetes have been previously reported, including the Bacillus sp. strain EBW4, isolated from the polychaete, $P$. aibuhitensis, which was shown to be a euryhaline marine microorganism capable of synthesizing amylase, protease, and lipase, and have the potential ability to degrade organic hydrocarbons (Shin et al., 2013). It was also reported that the extracellular enzymes produced by microorganisms in the excrement of $M$. sanguinea exhibited the ability to degrade polycyclic aromatic hydrocarbons (Onozato et al., 2012). The polychaete species, Nereis, can efficiently utilize unconsumed feed and fecal materials collected from a marine recirculating system (Bischoff et al., 2009). Furthermore, aquatic worms have been reported to play a key role in the bioremediation of sedimented waste in fish ponds (Kinoshita et al., 2008). Therefore, polychaetes are recognized as indicator organisms of marine pollution. As a result, the rockworm represents a beneficial resource due to its role in water purification and nutrient value.

Today, the useful microbial community as a component of biofloc system has been efficiently utilized in the aquaculture industry. On a dry weight basis, biofloc is composed of approximately $12 \%-50 \%$ proteins, $0.5 \%-41 \%$ lipids, $14 \%-59 \%$ carbohydrates, and $3 \%-61.4 \%$ ash according to differences in the composition between young and mature floc aggregates and the specific culture conditions (Biomin, 2020). The biofloc system is industrially utilized, especially in shrimp aquaculture in which biofloc is used as a natural food). Heterotrophs are the dominant species in biofloc due to their high growth rate. These microorganisms have been reported to play significant roles (Emerenciano et al., 2017), including the maintenance of water quality by converting nitrogenous waste into microbial proteins; providing a source of food by reducing the feed conversion ratio; and providing competition with potential pathogens.
Consequently, the biofloc system can not only treat uneaten feed through an in situ bioremediation process, but it can also reduce the content of dietary protein to support high density aquaculture while saving the expenses associated with water exchange and feed.

Although rockworms play an important role as a nutrient source to fish and crustaceans, as well as provide purification for marine pollutants, the microbial community in the rockworm gut and its association with biofloc feeding remains poorly understood. Therefore, identification of the microbial composition in the rockworm gut at each growth stage is required. In this study, an investigation of the rockworm gut flora and dominant flora at each growth stage was conducted to elucidate the changes that occur in the microbial community following different feeding behaviors as the rockworms grew and the influence of the gut flora on rockworm growth. Bioinformatics analyses were performed to assess the richness and diversity of the bacterial community at each growth stage. In addition, the bacterial community in the gut of the biofloc-fed adults was compared with that in the gut of adults fed regular feed to determine the influence of biofloc on the gut flora and exploit adult rockworms carrying useful gut flora.

\section{Material and Methods}

\section{Rockworm samples}

To investigate changes in the composition of the bacterial community of the rockworm at various stages of growth, Marphysa sanguinea was used as the source material. Rockworms were grown on regular feed, which contained crude protein (55\%), crude fat (13\%), crude fiber (1\%), calcium (1.6\%), phosphorus (1.4\%), sodium $(0.7 \%)$, omega 3 (35 mg/g dry weight), and crude ash (1\%). In parallel, rockworms were fed on biofloc culture at the adult stage to examine the influence of different nutrients on the gut flora. The biofloc was prepared in a 500 $\mathrm{L}$ tank under the following conditions: $\mathrm{C} / \mathrm{N}$ ratio (15-20 with molasses, sugar, and regular feed), DO (6.5-7.0 mg/L), pH (7-8), salinity (25-28 psu), alkalinity (150-200 mg/L), and sludge settling $(\mathrm{SV} 30<20 \mathrm{~mL} / \mathrm{L})$ at $25^{\circ} \mathrm{C}$. Rockworm samples at various growth stages (larva grown for 1-week, juveniles for 3-months, and adults for 12-months) and adult rockworm fed on the biofloc culture were collected from the Fishery Sciences Technology Center (Pukyong National University, Goseung, Korea). The collected live rockworms were first washed three times with $70 \%$ ethanol on a clean bench. For isolation of the 
microbial flora, samples were prepared using two methods: 1) larval rockworms were crushed using a loop; and 2) the gut regions of the rockworms grown to juvenile and adult were cut using a sterile knife. One gram of each prepared sample was stored at $-20^{\circ} \mathrm{C}$ for use in subsequent experiments.

\section{DNA extraction and next generation sequencing (NGS)}

To evaluate the microbial taxonomy, DNA was first extracted using a PowerSoil ${ }^{\circledR}$ DNA Isolation Kit (Cat. No. 12888, MO BIO, Seattle, WA, USA ) according to the manufacturer's protocol. For each sample representing the experimental group, V3V4 regions of the 16S rRNA gene were amplified by polymerase chain reaction (PCR) using 16S Amplicon PCR Forward Primer (5' TCGTCGGCAGCGTCAGATGTGTATAAGAGACAGCCTACGGGNGGCWGCAG) and 16S Amplicon PCR Reverse Primer (5' GTCTCGTGGGCTCGGAGATGTGTATAAGAGACAGGACTACHVGGGTATCTAATCC). These primers were designed to maintain approximately $50 \%$ of the guanine and cytosine content without the partially rich adenosine and thymine content to stably bind the template DNA. Input genomic DNA (gDNA) was amplified with 16S V3-V4 primers and a subsequent limited-cycle amplification step was performed to supplement the multiplexing indices and Illumina sequencing adapters (Illumina, San Diego, CA, USA). The final amplified products were normalized and pooled using the PicoGreen (Invitrogen, Carlsbad, CA, USA), and the library size was confirmed using TapeStation DNA screentape D1000 (Agilent, Santa Clara, CA, USA). Sequencing was then performed using the MiSeq ${ }^{\text {mit }}$ platform (Illumina, San Diego, CA, USA). The systematic bacterial community composition was determined based on the criteria of the Q30 Phred quality score (99.9\% certainty).

\section{Bioinformatics analysis}

After the complete sequencing, a FASTQ file of the MiSeq raw data was yielded using MCS software (MiSeq Control Software v2.2) and bcl2fastq (v1.8.4). The standard DNA PhiX sequence was eliminated through BWA. Paired-end reads acquired from the MiSeq system were incorporated using FLASH software. Low-quality, ambiguous, and chimera sequences were trimmed using CD-HIT-OUT, in which the operation taxonomic units (OTU) was formed by assembling over $97 \%$ of similar sequences. The assignment of taxonomy for each sample was conducted using BLASTN (v2.4.0) (National Center for Biotechnology Information [NCBI], Bethesda, MD, USA) with reference DB (NCBI 16S Microbial) and the microbial information for the most similar subjects. The taxonomy was determined when the query coverage of the best hit matching the $\mathrm{DB}$ was higher than $85 \%$ and the identity of the match area was higher than $85 \%$. In addition, various microbial communities were compared using QIIME (v1.8). Bacterial OTUs were generated using the UCLUST function in QIIME, and Venn diagrams were constructed with the application of the Venny 2.1 online program to compare the OTUs between groups. Using the above procedure, alpha diversity was obtained by a rarefaction curve. The richness of the bacterial community for each sample was calculated using a Chao estimator, and the diversity and the concentration of the species in the bacterial community was assessed based on Shannon and Simpson indices. For comparisons of sample diversity, beta diversity was assessed with weighted and unweighted UniFrac distance matrices and provided with a principal coordinate analysis (PCoA).

\section{Results and Discussion}

Based on the sequencing results, 1,932,884 of the total reads were obtained, within which 701,452, 456,258, 451,504, and 323,670 reads were obtained at the larval, juvenile, adult, and biofloc-fed adult growth stages, respectively. In the phylogenetic analysis of the $16 \mathrm{~S}$ rRNA gene clones, some of the identified gut flora could not be classified as unknown due to the impossibility of gene sequencing. The Q30 Phred quality score with $0.1 \%$ chance of an incorrect base call and the samples at the larval, juvenile, adult, and biofloc-fed adult growth stages were $78.87 \%$, $77.34 \%, 77.00 \%$, and $77.71 \%$, respectively.

\section{Composition of the bacterial community}

\section{Bacterial community at the phylum level}

The phylum level of the bacterial communities from the rockworm gut at various growth stages was obtained from the reads and presented in Fig. 1. The rockworm gut flora was observed to be consisted of diverse microbial species and the composition of the bacterial community was varied at each of the different growth stages. This indicates that the changes in the rockworm gut flora are dependent on both the amount of intake, as well as the type of feed. Therefore, feed is indispensable to form the composition of the gut microbiota and thus reconciles the inter-relationship between the gut microbiome and the host.

The dominant bacteria at the phylum level for each growth stage are listed in Table 1. The dominant phyla consisted of 


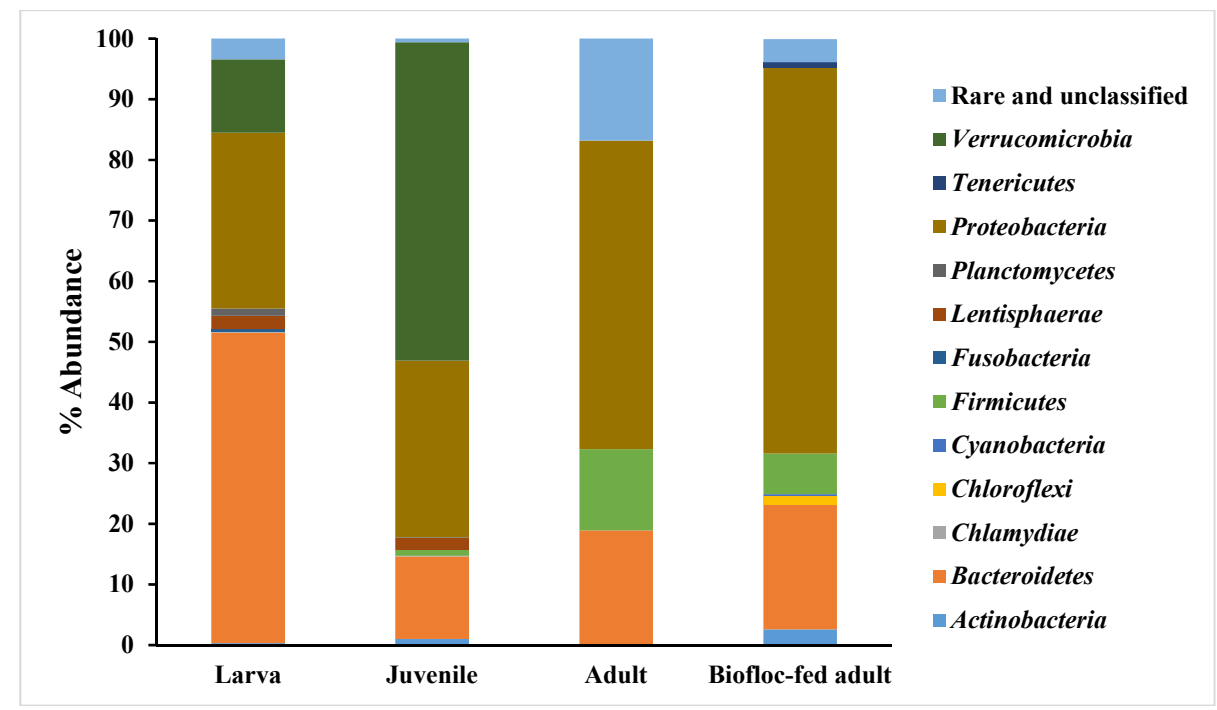

Fig. 1. Phylum levels of rockworm gut bacterial communities at various stages of growth.

Table 1. Percentage of indigenous bacteria present at each growth stage at the phylum level

\begin{tabular}{|c|c|c|c|c|}
\hline \multirow[t]{2}{*}{ Phylum level } & \multicolumn{4}{|c|}{ Percentage of indigenous bacteria at each rockworm growth stage (\%) } \\
\hline & Larva & Juvenile & Adult & Biofloc-fed adult \\
\hline Bacteroidetes & 51.21 & 13.60 & 18.80 & 20.62 \\
\hline Proteobacteria & 28.98 & 29.10 & 50.88 & 63.63 \\
\hline Verrucomicrobia & 12.08 & 52.54 & 0.00 & 0.00 \\
\hline Firmicutes & 0.05 & 0.96 & 13.37 & 6.71 \\
\hline
\end{tabular}

Bacteroidetes, Verrucomicrobia, Proteobacteria, and Proteobacteria at the larval, juvenile, adult, and biofloc-fed adult growth stages, respectively, with a significantly different composition, representing the variance in the bacterial community at different growth stages. During the rockworm growth stages, the Proteobacteria and Bacteroidetes phyla exhibited the highest relative abundance. Since these phyla have been reported to be ubiquitous bacteria in aquatic environments and aquaculture production systems (Zhou et al., 2017), the same tendency was observed in the rockworm gut. The Bacteroidetes group, including Flavobacteriaceae, was reported to possess the ability to adhere to various particles and produce extracellularly positioned degradative enzymes (Kirchman, 2002; Williams et al., 2012). The Proteobacteria group consists of several phototrophs and heterotrophs, with a high degradative ability for substances (e.g., methane and methanol) in aquatic environments (Martins et al., 2013), and the Proteobacteria group have been reported to be involved in nutrient recycling processes and the mineraliza- tion of organic components in aquatic systems (Cardona et al., 2016).

As the rockworms grow, the composition of the Firmicutes phylum gradually increased in the gut of the rockworms fed both regular feed and biofloc, especially during the adult stage. In the microbial communities of bioflocs used for shrimp culture, the Proteobacteria and Firmicutes phyla dominated the bacterial population (Kasan et al., 2017). Furthermore, the gut bacterial community in healthy shrimp is known to consist primarily of Proteobacteria (Landsman et al., 2019). The microbiome of shrimp and other aquatic species dominated by Proteobacteria has been reported to vary greatly from that of the terrestrial animals. Firmicutes and Bacteroides represent the most common phyla in terrestrial animals (Xiong et al., 2017), whereas these phyla and Actinobacteria are secondary contributors to the shrimp microbiome. However, the relative abundance of each species is highly dependent on environment and diet (Li et al., 2018). 
Between the adult-stage rockworms fed regular feed and those fed biofloc, there was a similar tendency regarding the relative abundance of the bacterial community. The Proteobacteria, Bacteroides, and Firmicutes phyla represented the major components in adult growth stage, and this has also been reported for biofloc produced from amaranth and wheat, in which these phyla with Planctomycetes exhibited relative abundance in the bacterial community (Vargas-Albores et al., 2019). As a result, these phyla can process nitrogenous and carbonaceous compounds simultaneously through a diverse number of pathways.

\section{Bacterial community at the family and genus levels}

Although the phylum level of the bacterial communities at various growth stages in the rockworm gut provides some useful information, the specific bacterial groups involved in the growth and health of rockworms remains poorly understood. Therefore, it is important to seek information related to bacterial communities at both the family and genus levels. Table 2 presents the bacterial composition at the family level for each growth stage. The Flavobacteriaceae and Vibrionaceae families were dominant at the larval stage; however, their occupancy in the bacterial community decreased as the rockworms grew. On the other hand, the occupancy of the Rhodobacteraceae and Pseudoalteromonadaceae families exhibited the opposite tendency; however, all of these families were not detected in the adults. Moreover, the families Flavobacteriaceae and Rhodobacteraceae inhabited the gut of biofloc-fed adults. In addition, the family, Mycoplasmataceae, detected at the lowest abundance in rockworms fed regular feed was found in the biofloc-fed adults. Members of the Rhodobacteraceae family can exhibit antagonistic activity, thereby limiting the survival of pathogenic Vibrio species (Pilotto et al., 2018). Rhodobacteraceae appeared to struggle with Vibrionaceae at the larval stage; however, the impact of Vibrionaceae may overwhelm Rhodobacteraceae, leading to a high mortality rate. Once the rockworms survived,
Vibrionaceae gradually disappeared. It was not surprising that a considerably different bacterial community formed in the biofloc-fed adults. The same phenomenon has been observed in biofloc-fed shrimp, in which the bacterial composition is richer and more diverse than that derived from clear seawater. Biofloc can be classified by size. In small-sized bioflocs $(<20 \mu \mathrm{m})$, some candidate pathogens (e.g., Vibrionaceae, Mycoplasmataceae, and Pseudoalteromonadaceae) have been detected, most of which exhibit a negative correlation with the shrimp growth parameters. In large-sized bioflocs (> $20 \mu \mathrm{m})$; however, some particle-bound bacteria, including Rhodobacteraceae and Flavobacteriaceae, are enriched to the greatest extent, and the majority of these taxa were strongly correlated with shrimp health or the environmental parameters of the water. In the healthy shrimp gut, the microbiotas were reported to be more similar to the bacterial communities of large-sized bioflocs. This indicates that the shrimp gut microbiota may be partially derived from large bioflocs particles, and bacteria driven by large particles may play an important role in promoting shrimp growth (Huang et al., 2020). Therefore, in biofloc-fed rockworms, the Flavobacteriaceae and Rhodobacteraceae families likely contribute to rockworm growth and simultaneously compete with the Mycoplasmataceae family, which has a negative impact on rockworm growth.

The genus level of the bacterial communities in the rockworm gut at various stages of growth are shown in Fig. 2, in which the genera comprising less than $1 \%$ occupancy are represented as others. Based on our findings, an obvious shift in the gut bacterial community was observed as the rockworms grew, and the same pattern was also found at the phylum level. The dominant genera at each growth stage consisted of: Rubritalea, Vibrio, and Catenococcus at the larval stage; Rubritalea, Psedoalteromonas, and Persicirhabdus at the juvenile stage; Delftia, Campylobacter, and Butyrivibrio at the adult stage; and Acinetobacter, Delftia, and Acidovorax at the biofloc-fed adult stage.

Table 2. Percentage of indigenous bacteria present at each growth stage at the family level

\begin{tabular}{lllll}
\hline \multirow{2}{*}{ Family level } & \multicolumn{3}{l}{ Percentage of indigenous bacteria at each rockworm growth stage (\%) } \\
\cline { 2 - 5 } & Larva & Juvenile & Adult & Biofloc-fed adult \\
\hline Flavobacteriaceae & 48.21 & 10.23 & 0.00 & 13.43 \\
Vibrionaceae & 15.59 & 4.51 & 0.00 & 0.00 \\
Rhodobacteraceae & 3.16 & 10.17 & 0.00 & 1.74 \\
Pseudoalteromonadaceae & 2.68 & 5.47 & 0.00 & 0.00 \\
Mycoplasmataceae & 0.00 & 0.00 & 0.00 & 0.86 \\
\hline
\end{tabular}



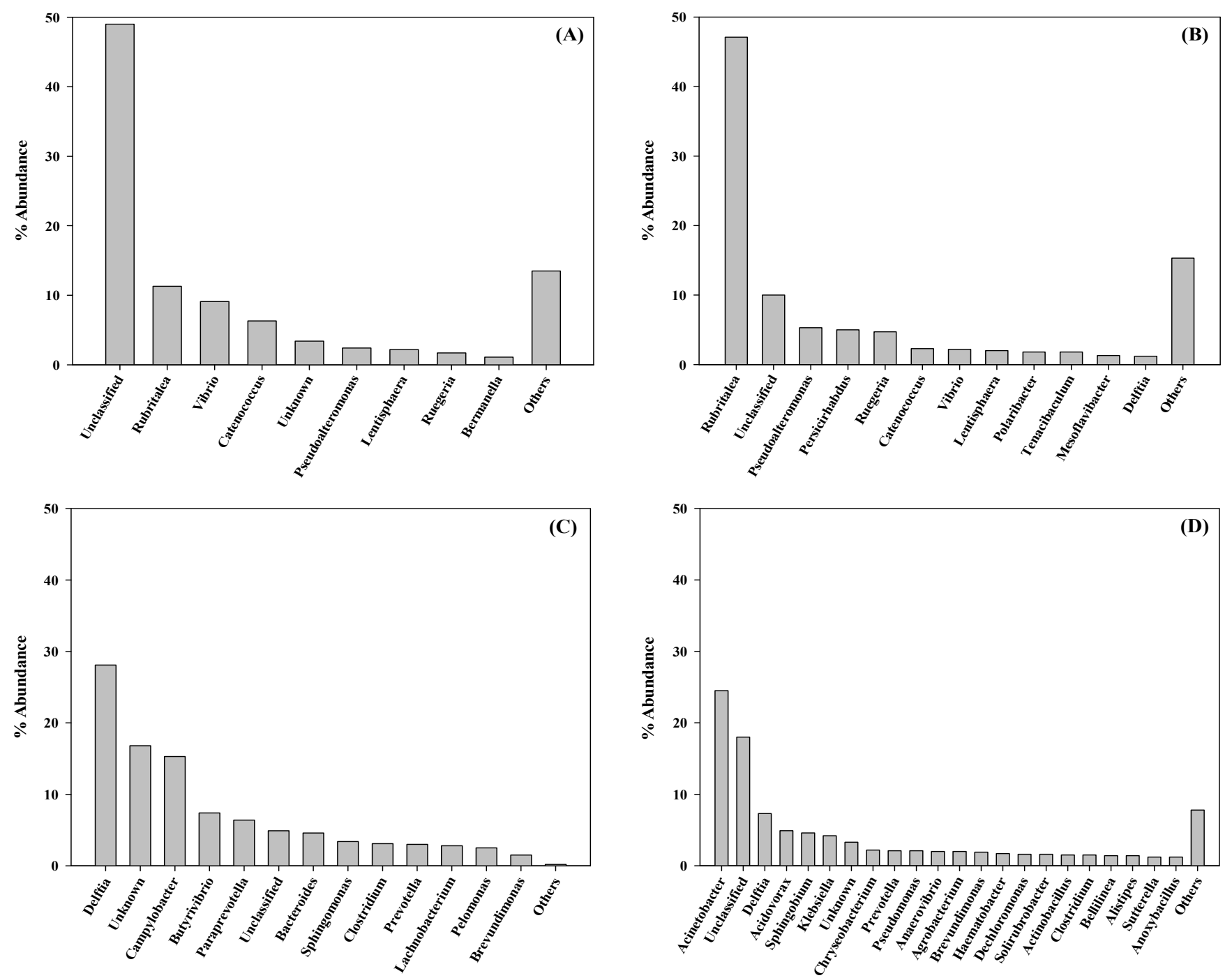

Fig. 2. Genus levels of rockworm gut bacterial communities at various growth stages: (A) larval, (B) juvenile, (C) adult, and (D) biofloc-fed adult stages.

Members of the Bacteroides genus were distinctly detected (by $4.56 \%)$ only in adults fed regular feed, which can use a variety of carbohydrates as an energy source (Chen et al., 2020). Our findings indicate that the Vibrio genus was the most abundant $(9.15 \%)$ at the larval stage, which was substantially reduced to $2.17 \%$ at the juvenile stage, and it was minimally detected in the adult rockworms fed either regular feed or biofloc. The Vibrio genus is composed of fast-growing aquatic Gram-negative bacteria and it is able to colonize the digestive tract of various animals. In shrimp aquaculture, many Vibrio species have been implicated in various gastro-intestinal diseases under conditions of poor nutrition, low water quality, and immunosuppression, leading to high mortality (Pilotto et al., 2018). Furthermore, the emergence of multiple resistant strains against Vibrio species has been reported due to the indiscriminate use of antibiotics to protect the farms from bacteriosis. Today, biofloc technology represents an eco-friendly alternative for the control of infectious diseases. Microorganisms present in bioflocs can function as natural probiotics and protect against pathogens through competition for nutrients, production of inhibitory compounds, and interference with bacterial quorum-sensing communication (Pilotto et al., 2018). Based on the above facts, the high mortality of rockworms during the larval stage may be associated with the abundance of the Vibrio genus. Another important point to 
note is that the microbiota of the biofloc-fed adult rockworm was characterized by the highest diversity, in contrast to larval, juvenile, and adult-stage rockworms. Therefore, biofloc could contribute to rockworm growth, since the high diversity of the microbiota is generally regarded as beneficial for host health (Niu et al., 2020).
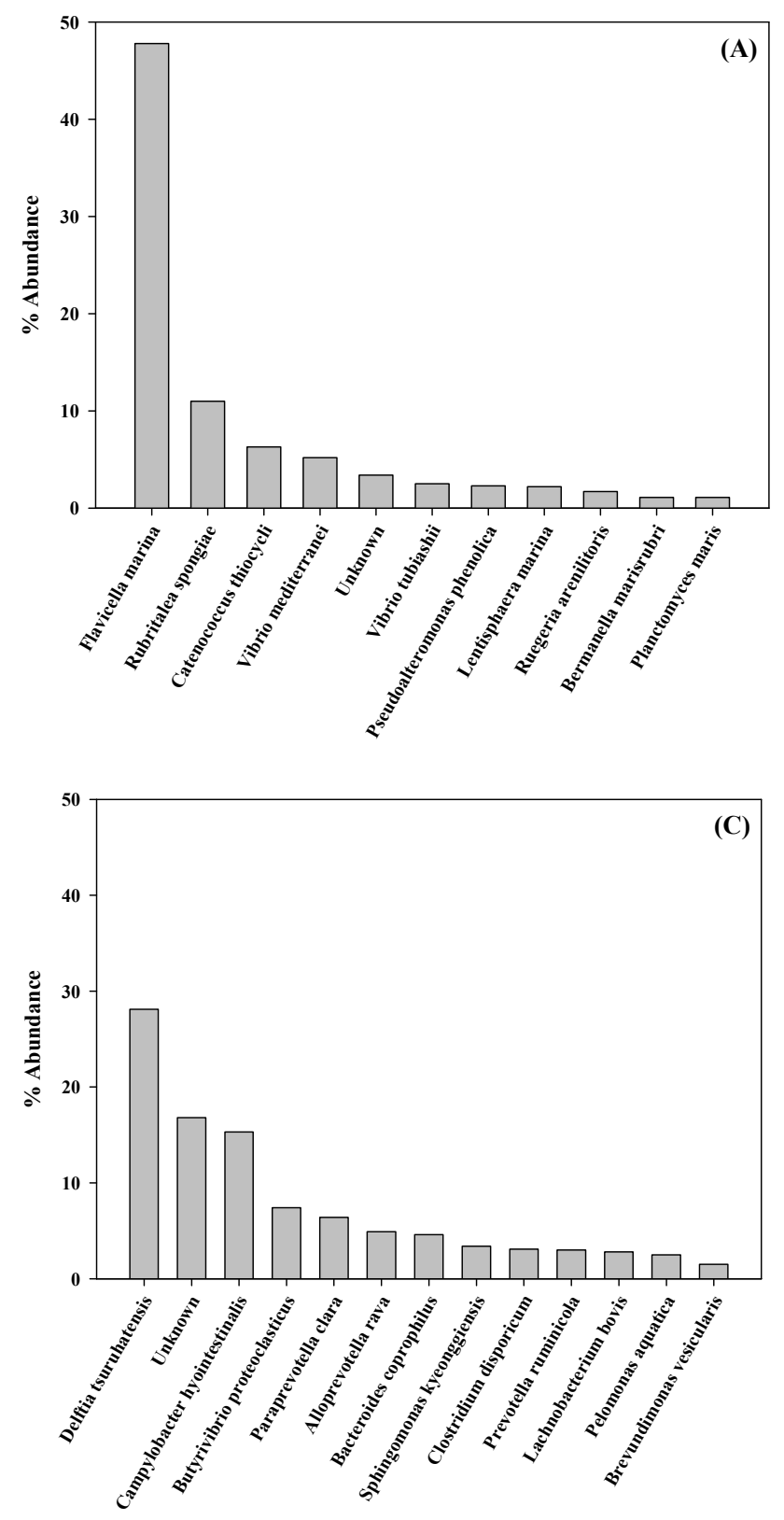

\section{Bacterial community at the species level}

The bacterial community at the species level in the gut of rockworm was investigated at each growth stage (Fig. 3) and 10 abundant species are exhibited in Table 3. Flavicella marina (47.8\%), Rubritalea spongiae (11.0\%), and Catenococcus thiocycli $(6.3 \%)$ were the three most abundant species in the gut at the
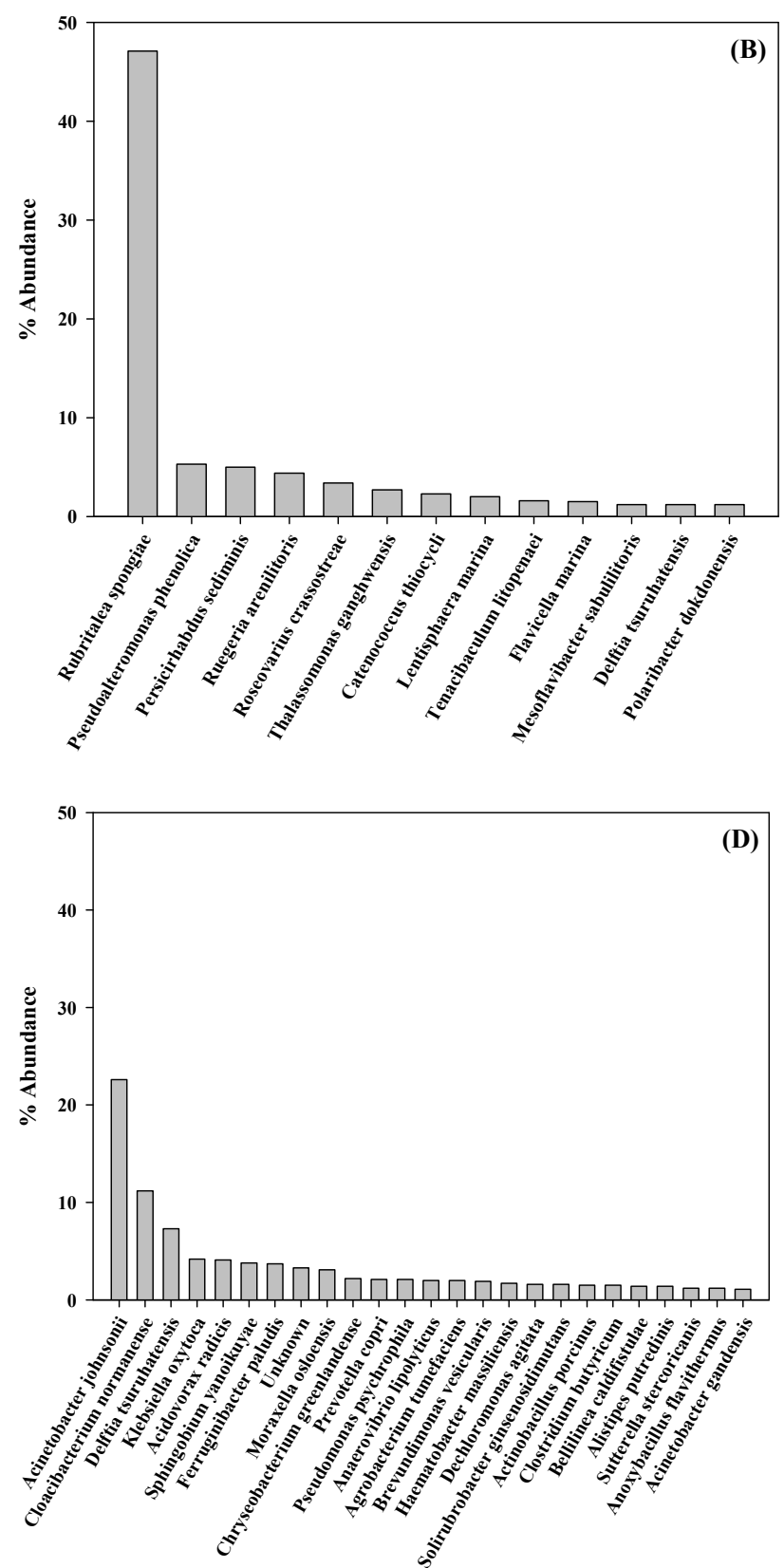

Fig. 3. Species levels of rockworm gut bacterial communities at various growth stages: (A) larval, (B) juvenile, (C) adult, and (D) biofloc-fed adult stages. 
Table 3. Ten bacterial species abundantly present in the rockworm gut at each growth stage

\begin{tabular}{|c|c|c|c|c|}
\hline \multirow[t]{2}{*}{ Bacterial species } & \multicolumn{4}{|c|}{ Abundance of bacterial species at each rockworm growth stage (\%) } \\
\hline & Larva & Juvenile & Adult & Biofloc-fed adult \\
\hline Flavicella marina & 47.8 & 1.5 & - & - \\
\hline Rubritalea spongiae & 11.0 & 47.1 & - & - \\
\hline Catenococcus thiocycli & 6.3 & 2.3 & - & - \\
\hline Vibrio mediterranei & 5.2 & - & - & - \\
\hline Vibrio tubiashii & 2.5 & - & - & - \\
\hline Pseudoalteromonas phenolica & 2.3 & 5.3 & - & - \\
\hline Lentisphaera marina & 2.2 & - & - & - \\
\hline Ruegeria arenilitoris & 1.7 & 4.4 & - & - \\
\hline Bermanella marisrubri & 1.1 & - & - & - \\
\hline Planctomyces maris & 1.1 & - & - & - \\
\hline Persicirhabdus sediminis & - & 5.0 & - & - \\
\hline Roseovarius crassostreae & - & 3.4 & - & - \\
\hline Thalassomonas ganghwensis & - & 2.7 & - & - \\
\hline Lentisphaera marina & - & 2.0 & - & - \\
\hline Tenacibaculum litopenaei & - & 1.6 & - & - \\
\hline Delftia tsuruhatensis & - & - & 28.1 & 7.3 \\
\hline Campylobacter hyointestinalis & - & - & 15.3 & - \\
\hline Butyrivibrio proteoclasticus & - & - & 7.4 & - \\
\hline Paraprevotella clara & - & - & 6.4 & - \\
\hline Alloprevotella rava & - & - & 4.9 & - \\
\hline Bacteroides coprophilus & - & - & 4.6 & - \\
\hline Sphingomonas kyeonggiensis & - & - & 3.4 & - \\
\hline Clostridium disporicum & - & - & 3.1 & - \\
\hline Prevotella ruminicola & - & - & 3.0 & - \\
\hline Lachnobacterium bovis & - & - & 2.8 & - \\
\hline Acinetobacter johnsonii & - & - & - & 22.6 \\
\hline Cloacibacterium normanense & - & - & - & 11.2 \\
\hline Klebsiella oxytoca & - & - & - & 4.2 \\
\hline Acidovorax radices & - & - & - & 4.1 \\
\hline Sphingobium yanoikuyae & - & - & - & 3.8 \\
\hline Ferruginibacter paludis & - & - & - & 3.7 \\
\hline Moraxella osloensis & - & - & - & 3.1 \\
\hline Chryseobacterium greenlandense & - & - & - & 2.2 \\
\hline Prevotella copri & - & - & - & 2.1 \\
\hline Unknowns ${ }^{1)}$ & 3.4 & 0.6 & 16.8 & 3.3 \\
\hline
\end{tabular}

1) Bacterial species present in the rockworm gut at less than $1 \%$ abundance.

larval stage, whereas R. spongiae (47.1\%), Pseudoalteromonas phenolica (5.3\%), and Persicirhabdus sediminis (5.0\%) were the most abundant at the juvenile stage; however, these species were only detected at minimal levels in the gut of rockworms fed either the regular feed or biofloc. At the adult stage, the top three most abundant species were Delftia tsuruhatensis (28.1\%), Campylobacter hyointestinalis (15.3\%), and Butyrivibrio proteoclasticus (7.4\%) from the rockworm fed regular feed, and Acinetobacter johnsonii (22.6\%), Cloacibacterium normanense (11.2\%) and D. tsuruhatensis (7.3\%) from the biofloc-fed rock- 
worms, respectively. Therefore, the bacterial species exhibited some overlap during the early growth stages, but became highly diverse in the later growth stages. Microbial community shifts in the gut flora is known to be due to feed changes, age, and antibiotics (Hasan \& Yang, 2019). To date, the studies reporting the interaction between earthworm species and the environment indicate that the bacterial community at the gut wall can be altered by the type of food resources and habitat (Thakuria et al., 2010). This indicates that the increase in the diversity of the rockworm gut flora could be derived from the increased food intake by rockworms after the juvenile stage (Aira et al., 2016).

At the larval stage, the Vibrio species (V. mediterranei and V. tubiashii) occupied $7.7 \%$ of the bacterial community. These Vibrio species are considered to be causative agents of various diseases, which are particularly associated with the mortality of aquatic animals (e.g., bivalves and fish) (Andree et al., 2021). These findings imply that Vibrio species may directly affect the high mortality of rockworm at the larval stage. Pseudoalteromonas phenolica was also detected at the larval stage with an abundance of $2.3 \%$, and its abundance increased by more than two-fold (5.3\%) at the juvenile stage. This species is associated with strain pigmentation and has been known to possess antimicrobial activity (Bowman, 2007). Therefore, P. phenolica may play a role in reducing the high mortality of rockworm. At the juvenile stage, the abundance of Ruegeria arenilitoris increased by 2.6 times $(1.7 \%)$ compared to that exhibited at the larval stage. Moreover, $R$. arenilitoris is commonly found in rockworm that can withstand various levels of salinity, since it is a moderate halophile which grows in the presence of $0.5 \%-2 \% \mathrm{NaCl}$ (Park \& Yoon, 2012). Furthermore, Roseovarius crassostreae was found to occupy $3.4 \%$ of the bacterial community at the juvenile stage, despite an extremely low abundance observed during the larval stage. $R$. crassostreae has been shown to cause high seasonal mortality in oyster juveniles (Modak \& Gomez-Chiarri, 2020). In addition, as the rockworms grew, the juvenile stage was associated with a significant increase in the abundance of R. spongiae. R. spongiae is known to be able to survive at a wide range of temperatures $\left(4^{\circ} \mathrm{C}-37^{\circ} \mathrm{C}\right.$ ) and salinity (up to $7 \%$ ) (Yoon et al., 2007). This characteristic may explain its high abundance in the rockworm gut.

At the adult stage, there was a high occupancy (16.8\%) of unknown bacterial species (less than $1 \%$ abundance in the rockworm gut), implying an increase in the diversity of the bacterial community. Specifically, D. tsuruhatensis was the dominant species in the gut of rockworms fed regular feed and biofloc by
$28.1 \%$ and $7.3 \%$, respectively. This species is known to reduce substances accounting for biologically-induced taste and odor problems (Sompong et al., 2018). The second most abundant species (15.3\%) present in the gut of rockworms fed the regular feed was Campylobacter hyointestinalis, which has been implicated as a pathogen in gastroenteritis and diarrhea in humans (Edmonds et al., 1987); however, this species was only detected at low levels in the gut of the biofloc-fed rockworms. This indicates that the microbiota of the biofloc-fed rockworm play an important role in controlling potential pathogenic species, thereby contributing to rockworm growth.

In the gut of rockworms fed the regular feed, Butyrivibrio proteoclasticus was the next most abundant species (7.4\% abundance), which is known to degrade polysaccharides to produce butyrate (Kelly et al., 2010). In addition, proteolytic Clostridium disporicum was identified to exhibit an abundance of 3.1\%; however, these two species were only minimally detected in the gut of the biofloc-fed rockworms. Moreover, Prevotella ruminicola was found to occupy $3.0 \%$ of the bacterial community, which is known to play a significant role in the metabolism of proteins and peptides in the rumen (Wallace et al., 1997); however, this species was not identified in the gut of biofloc-fed rockworms; instead, Prevotella copri was detected with $2.1 \%$ abundance. This gut microbe species was reported to have immune relevance in patients with rheumatoid arthritis (Pianta et al., 2017). Therefore, this species may be involved in immune activity that is beneficial to rockworms.

In the gut of the biofloc-fed adults, phosphate-accumulating Acinetobacter johnsonii was the most abundant (22.6\%) species, which was minimally identified in rockworms fed the regular feed throughout the entire growth stages; however, this finding is not surprising since it was also found to be enriched in the sediment from healthy shrimp (Cornejo-Granados et al., 2017). Therefore, the formation of the rockworm gut flora was closely dependent upon the type of feed. Cloacibacterium normanense was the next most abundant species present in the gut (11.2\%), which is known to play a role in phosphate removal (Gay et al., 2016). Klebsiella oxytoca, Sphingomonas yanoikuyae, and Moraxella osloensis were detected at an abundance of $4.2 \%$, $3.8 \%$, and $3.1 \%$, respectively. K. oxytoca has been shown to have the ability to effectively remove nitrite (Liu et al., 2013), whereas S. yanoikuyae is notable for its capacity to degrade a variety of aromatic compounds (Rentz et al., 2008). However, M. osloensis represents a known opportunistic human pathogen involved in several human diseases (Tan \& Grewal, 2002). As a result, the 
biofloc-fed adults harbored bacterial species beneficial for water purification and may represent an excellent candidate for the enhancement of water and nutrient recycling. Recently, integrated multitrophic aquaculture (IMTA) has been shown to efficiently reduce the impact of nutrient loading on water quality. The juvenile polychaete worm, Nereis, and lugworm have been reported to exhibit effective performance in the recycling the organic particles generated from other components in the IMTA system (Bischoff et al., 2009; Aquaculture in Canada, 2013). The co-culture of juvenile rockworms ( $M$. sanguinea) and olive flounder (Paralichythys olivaceus) in the IMTA system has also been reported (Parandavar et al., 2018). The ability of these species to participate in the decomposition and mineralization of organic sediment was suitable for recovery in impacted coastal aquaculture sites, contributing towards a more sustainable and productive form of aquaculture. Based on the above results, it can be determined that biofloc represents an important food source for the survival, growth rate, and reproduction of rockworms. Moreover, the benefits of biofloc-fed rockworms can be applied to maximize the potential of the IMTA system in terms of productivity and to simultaneously diminish the organic materials released into the marine environment.

\section{Diversity analyses of bacterial communities}

\section{Venn diagram of bacterial communities}

The Venn diagram revealed that two species (D. tsuruhatensis and P. acnes) were common to all groups at the species level (Fig. 4). This indicates that most OTUs were not shared among the four groups. The highest number of differentiated OTU sequences was detected at the larval stage, which had the richest microbial communities. Another 63 bacterial species were shared between the larva and juvenile stages, exhibiting relative similarity. On the other hand, only four species were shared between the larval and adult bacterial groups. Furthermore, bacterial species uniquely identified in the rockworm gut consisted of 184, 74, 10, and 35 species in the larva, juvenile, adult, and biofloc-fed adult groups, respectively. Consequently, there was a distinct shift in the bacterial composition of the rockworm gut, which was dependent on the amount of intake and composition of food (Aira et al., 2016). During the early growth phases, aquatic microorganisms were found to affect the composition of the gut microbiota, causing high mortality rates. After overcoming this critical point, rockworms increased their rate of food intake, which altered the composition of the gut

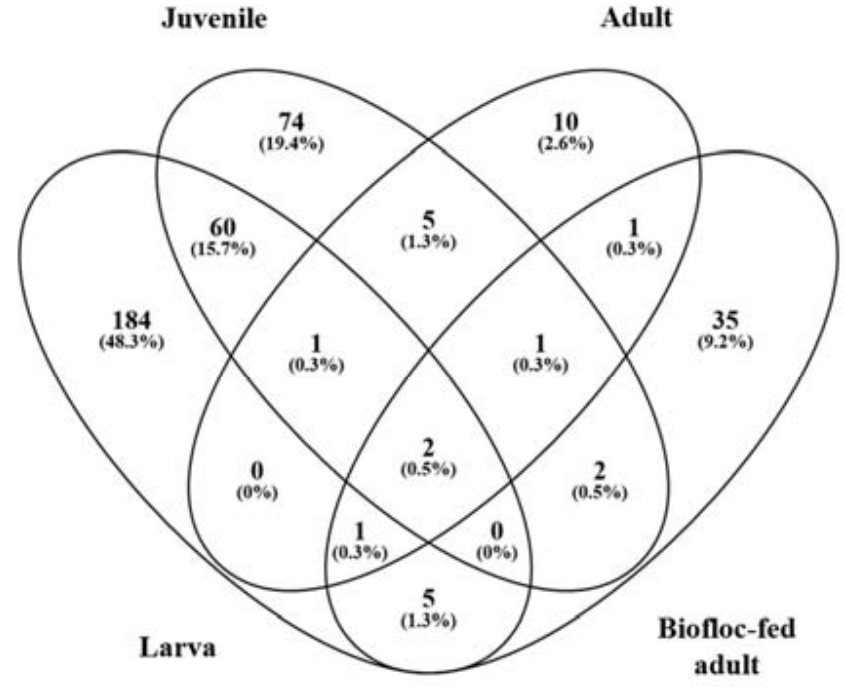

Fig. 4. Venn diagram showing the unique and shared OTUs from the rockworm gut at larval, juvenile, adult, and bioflocfed adult stages. OTU, operation taxonomic units.

microbiota, and beneficial bacterial groups (for nutrient intake, innate immunity, and pathogen defense) naturally increased their occupancy in the gut of healthy rockworms.

\section{Alpha-diversity in bacterial communities}

The alpha-diversity in the bacterial communities of the rockworm gut are shown in Table 4, in which the good coverage values of all samples were close to 1 , representing a high level of accuracy. The results of the OTUs revealed that the bacterial species in the rockworm gut decreased as the rockworms grew; however, the number of species increased in the biofoc-fed rockworms. This indicates that the rockworm gut was occupied by relatively few species, despite the diverse bacterial distribution during the larval stage. This result was in agreement with the results of OTUs. The results of the Chao index revealed that the bacterial species in rockworm gut flora was the richest during the larval stage and tended to become less rich during the later growth stages. This indicates that while more active food intake during the later growth stages resulted in a decreased richness of bacterial species, there was an increase in the diversity of the bacterial community. This increase in bacterial community diversity was favorably revealed by the results of the Simpson index, in which the diversity of the bacterial community was the highest in the gut flora of biofloc-fed adults, which exhibited the highest equal distribution. Moreover, the Shannon 
Table 4. Alpha-diversity of the rockworm gut bacterial communities

\begin{tabular}{llllll}
\hline Sample & OTUs & Chao1 & Shannon & Simpson & Good's coverage \\
\hline Larva & 253.00 & 254.50 & 3.65 & 0.75 & 0.99 \\
Juvenile & 145.00 & 148.00 & 3.91 & 0.77 & 0.99 \\
Adult & 21.00 & 21.00 & 3.46 & 0.87 & 1.00 \\
Biofloc-fed adult & 47.00 & 47.00 & 4.55 & 0.92 & 1.00 \\
\hline
\end{tabular}

OTU, operation taxonomic units.

index revealed that the diversity of the bacterial community in the gut flora of rockworms fed regular feed was the highest during the juvenile stage, with less richness of bacterial species. However, the diversity of the bacterial community in the gut flora was elevated to a greater extent in the biofloc-fed adults. Inevitably, aquatic microorganisms affect the composition of the gut microbiota, which plays an invaluable role in maintaining nutrient absorption, innate immunity, and pathogen defense. In this study, the bacterial species present in the bioflocs were ingested by the rockworms, influencing the gut microbiota and the physiological functions of the rockworms (Huang et al., 2020). Based on the results of the OTUs and distribution of bacterial species, the highest diversity of bacterial species was exhibited in the biofloc-fed adults.

\section{Beta-diversity in bacterial communities}

The PCoA was performed for samples at various growth stages, and the resultant diagram is shown in Fig. 5A. The PCoA for the sample groups from various growth stages revealed that the adult and biofloc-fed adult groups were located relatively close together, implying a similar rockworm gut flora between the two groups. This result was verified by the observation of high similarity between the samples in the PCoA and unweighted pair group method with arithmetic mean (UPGMA) tree (Fig. $5 \mathrm{~B}$ ). The arithmetic mean value between early (from larva to juvenile) and later (adult) growth stages was 0.1511. Similarly, the arithmetic mean value between the larval and juvenile growth stages was 0.131 , whereas that between the adult and biofloc-fed adult was 0.0998 . Therefore, the rockworm gut flora was the most similar between adults fed regular feed and biofloc. In contrast, both the larval and juvenile groups had low similarity with the other groups. Therefore, the same trend was drawn from the both approaches.

\section{Conclusion}

The composition and diversity of the rockworm gut flora was
(A)

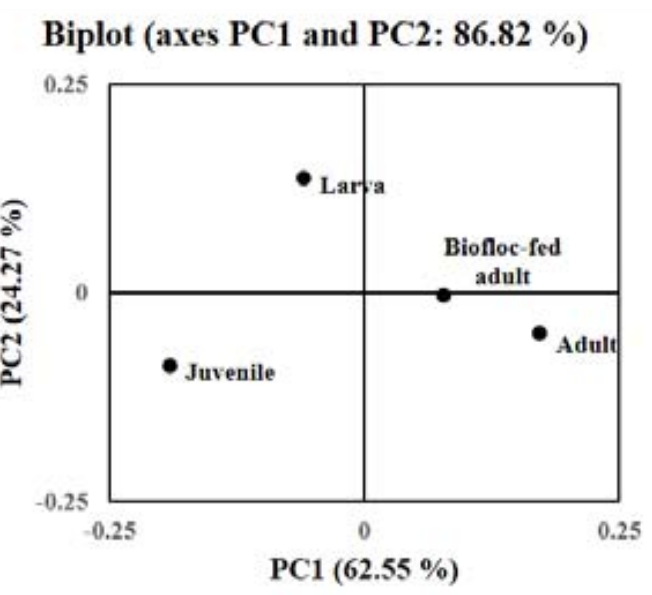

(B)

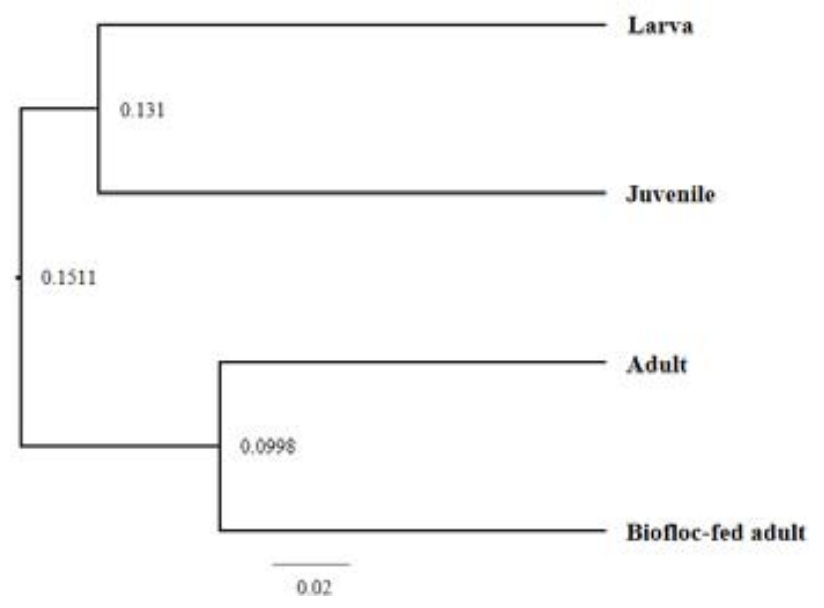

Fig. 5. Results of the principal component analysis for sample groups from various growth stages. Principal coordinate analysis $(P C O A)(A)$ and unweighted pair group method with arithmetic mean (UPGMA) tree (B) based in UniFrac metrics comparing gut microbiota samples from the larval, juvenile, adult, and biofloc-fed adult rockworms.

identified throughout each of the growth stages. As the rockworms grew, the composition of the gut flora varied consider- 
ably due to the type of feed and intake, which was confirmed at the phylum, family, genera, and species levels of the bacterial communities. The bioinformatics analysis also revealed that only two bacterial species were shared during the entire growth stages and biofloc-fed adults exhibited the highest bacterial community diversity. Potential pathogens, including Vibrio species, were identified primarily at the larval stage, but were rare in the healthy adult gut. Biofloc was observed to provide the adult rockworm gut with prominent immune relevant and water-purifying bacteria. Since the gut flora of the biofloc-fed adults had the ability to decompose and mineralize organic sediment, they can be effectively utilized for recovery in sites impacted by coastal aquaculture (e.g., IMTA) to contribute towards a more sustainable and productive form of aquaculture. Therefore, a better understanding of the usefulness of the rockworm gut flora may provide an opportunity to extend the application of biofloc-fed rockworms.

\section{Competing interests}

No potential conflict of interest relevant to this article was reported.

\section{Funding sources}

This work was supported by a Research Grant of Pukyong National University (Year 2019).

\section{Acknowledgements}

Not applicable.

\section{Availability of data and materials}

Upon reasonable request, the datasets of this study can be available from the corresponding author.

\section{Ethics approval and consent to participate}

This article does not require IRB/IACUC approval because there are no human and animal participants.

\section{ORCID}

Hyun Yi Jung https://orcid.org/0000-0002-7353-9096

Chang Hoon Kim https://orcid.org/0000-0002-6247-4733

Joong Kyun Kim https://orcid.org/0000-0001-7070-9507

\section{References}

Aira M, Olcina J, Pérez-Losada M, Domínguez J. Character- ization of the bacterial communities of casts from Eisenia andrei fed with different substrates. Appl Soil Ecol. 2016;98:103-11.

Andree KB, Carrasco N, Carella F, Furones D, Prado P. Vibrio mediterranei, a potential emerging pathogen of marine fauna: investigation of pathogenicity using a bacterial challenge in Pinna nobilis and development of a species-specific PCR. J Appl Microbiol. 2021;130:617-31.

Aquaculture in Canada. Integrated multi-trophic aquaculture (IMTA) [Internet]. 2013 [cited 2021 Jan 6]. http://www.dfompo.gc.ca/aquaculture/sci-res/imta-amti/imta-amti-eng. htm

Biomin. Sustainable shrimp farming: high density, biofloc-dominated, no-water-exchange systems [Internet]. 2020 [cited 2020 Dec 15]. https://www.biomin.net/science-hub/sustainable-shrimp-farming-high-density-biofloc-dominated-no-water-exchange-systems

Bischoff AA, Fink P, Waller U. The fatty acid composition of Nereis diversicolor cultured in an integrated recirculated system: possible implications for aquaculture. Aquaculture. 2009;296:271-6.

Bowman JP. Bioactive compound synthetic capacity and ecological significance of marine bacterial genus Pseudoalteromonas. Mar Drugs. 2007;5:220-41.

Cardona E, Gueguen Y, Magré K, Lorgeoux B, Piquemal D, Pierrat $\mathrm{F}$, et al. Bacterial community characterization of water and intestine of the shrimp Litopenaeus stylirostris in a biofloc system. BMC Microbiol. 2016;16:157.

Chen X, Luo G, Tan J, Tan H, Yao M. Effects of carbohydrate supply strategies and biofloc concentrations on the growth performance of African catfish (Clarias gariepinus) cultured in biofloc systems. Aquaculture. 2020;517:734808.

Cornejo-Granados F, Lopez-Zavala AA, Gallardo-Becerra L, Mendoza-Vargas A, Sánchez F, Vichido R, et al. Microbiome of Pacific Whiteleg shrimp reveals differential bacterial community composition between wild, aquacultured and AHPND/EMS outbreak conditions. Sci Rep. 2017;7:11783.

Edmonds P, Patton CM, Griffin PM, Barrett TJ, Schmid GP, Baker CN, et al. Campylobacter hyointestinalis associated with human gastrointestinal disease in the United States. J Clin Microbiol. 1987;25:685-91.

Emerenciano MGC, Martínez-Córdova LR, Martínez-Porchas M, Miranda-Baeza A. Biofloc technology (BFT): a tool for water quality management in aquaculture. In: Hlanganani T, editor. Water quality. London: Intech; 2017. p. 91-109. 
Gay NR, Fleming E, Oh J. Draft genome sequence of Cloacibacterium normanense NRS-1 isolated from municipal wastewater. Genome Announc. 2016;4:e01397-16.

Hasan N, Yang H. Factors affecting the composition of the gut microbiota, and its modulation. Peer J. 2019;7:e7502.

Huang L, Guo H, Chen C, Huang X, Chen W, Bao F, et al. The bacteria from large-sized bioflocs are more associated with the shrimp gut microbiota in culture system. Aquaculture. 2020;523:735159.

Kasan NA, Ghazali NA, Ikhwanuddin M, Ibrahim Z. Isolation of potential bacteria as inoculum for biofloc formation in Pacific whiteleg shrimp, Litopenaeus vannamei culture ponds. Pak J Biol Sci. 2017;20:306-13.

Kelly WJ, Leahy SC, Altermann E, Yeoman CJ, Dunne JC, Kong $\mathrm{Z}$, et al. The glycobiome of the rumen bacterium Butyrivibrio proteoclasticus $\mathrm{B} 316^{\mathrm{T}}$ highlights adaptation to a polysaccharide-rich environment. PLOS ONE. 2010;5:e11942.

Kinoshita K, Tamaki S, Yoshioka M, Srithonguthai S, Kunihiro T, Hama D, et al. Bioremediation of organically enriched sediment deposited below fish farms with artificially mass-cultured colonies of a deposit-feeding polychaete Capitella sp. I. Fish Sci. 2008;74:77-87.

Kirchman D. The ecology of Cytophaga-flavobacteria in aquatic environments. FEMS Microbiol Ecol. 2002;39:91-100.

Landsman A, St-Pierre B, Rosales-Leija M, Brown M, Gibbons W. Impact of aquaculture practices on intestinal bacterial profiles of Pacific whiteleg shrimp Litopenaeus vannamei. Microorganisms 2019;7:93.

Li E, Xu C, Wang X, Wang S, Zhao Q, Zhang M, et al. Gut microbiota and its modulation for healthy farming of Pacific white shrimp Litopenaeus vannamei. Rev Fish Sci Aquac. 2018;26:381-99.

Liu Y, Zang Y, Long X. High nitrite removal capacity of an aerobic denitrifier Klebsiella oxytoca DF-1 isolated from aquaculture ponds in coastal mudflats. Afr J Microbiol Res. 2013;7:1527-34.

Martins P, Cleary DFR, Pires ACC, Rodrigues AM, Quintino V, Calado R, et al. Molecular analysis of bacterial communities and detection of potential pathogens in a recirculating aquaculture system for Scophthalmus maximus and Solea senegalensis. PLOS ONE. 2013;8:e80847.

McFall-Ngai M, Hadfield MG, Bosch TCG, Carey HV, Domazet-Lošo T, Douglas AE, et al. Animals in a bacterial world, a new imperative for the life sciences. Proc Natl Acad Sci USA. 2013;110:3229-36.
Modak TH, Gomez-Chiarri M. Contrasting immunomodulatory effects of probiotic and pathogenic bacteria on Eastern oyster, Crassostrea virginica, larvae. Vaccines. 2020;8:588.

Niu KM, Lee BJ, Kothari D, Lee WD, Hur SW, Lim SG, et al. Dietary effect of low fish meal aquafeed on gut microbiota in olive flounder (Paralichthys olivaceus) at different growth stages. MicrobiologyOpen. 2020;9:e992.

Onozato M, Sugawara T, Nishigaki A, Ohshima S. Study on the degradation of polycyclic aromatic hydrocarbons (PAHs) in the excrement of Marphysa sanguinea. Polycycl Aromat Compd. 2012;32:238-47.

Parandavar H, Rahman M, Phoo WW, Kim CH. Effects of growth on polychaete rockworm, Marphysa sanguinea integrated culture with olive flounder, Paralichythys olivaceus in flow through system. J Aquac Res Dev. 2018;9:558.

Park S, Yoon JH. Ruegeria arenilitoris sp. nov., isolated from the seashore sand around a seaweed farm. Antonie van Leeuwenhoek. 2012;102:581-9.

Pianta A, Arvikar S, Strle K, Drouin EE, Wang Q, Costello CE, et al. Evidence of the immune relevance of Prevotella copri, a gut microbe, in patients with rheumatoid arthritis. Arthritis Rheum. 2017;69:964-75.

Pilotto MR, Goncalves ANA, Vieira FN, Seifert WQ, Bachère E, Rosa RD, et al. Exploring the impact of the biofloc rearing system and an oral WSSV challenge on the intestinal bacteriome of Litopenaeus vannamei. Microorganisms. 2018;6:83.

Prevedelli D. Influence of temperature and diet on the larval development and growth of juveniles Marphysa sanguinea (Montagu) (Polychaeta, Eunicidae). Nat Mar Biol Lib. 1994;162:521-6.

Rentz JA, Alvarez PJJ, Schnoor JL. Benzo[a]pyrene degradation by Sphingomonas yanoikuyae JAR02. Environ Pollut. 2008;151:669-77.

Shin S, Yundendorj K, Lee SS, Lee DH, Kang KH, Kahng HY. Characterization and organic hydrocarbons degradation potential of euryhaline marine microorganism, Bacillus sp. EBW4 isolated from polychaete (Perinereis aibuhitensis). Korean J Microbiol. 2013;49:38-45.

Sompong U, PongUdom P, Whangchai N. Microbial degradation of musty odor in aquaculture pond. Int J Agric Technol. 2018;14:1949-60.

Tan L, Grewal PS. Endotoxin activity of Moraxella osloensis against the grey garden slug, Deroceras reticulatum. Appl Environ Microbiol. 2002;68:3943-7. 
Thakuria D, Schmidt O, Finan D, Egan D, Doohan FM. Gut wall bacteria of earthworms: a natural selection process. ISME J. 2010;4:357-66.

Vargas-Albores F, Martínez-Córdova LR, Gollas-Galván T, Garibay-Valdez E, Emerenciano MGC, Lago-Leston A, et al. Inferring the functional properties of bacterial communities in shrimp-culture bioflocs produced with amaranth and wheat seeds as fouler promoters. Aquaculture. 2019;500:107-17.

Wallace RJ, McKain N, Broderick GA, Rode LM, Walker ND, Newbold CJ, et al. Peptidases of the rumen bacterium, Prevotella ruminicola. Anaerobe. 1997;3:35-42.

Williams TJ, Long E, Evans F, DeMaere MZ, Lauro FM, Raftery MJ, et al. A metaproteomic assessment of winter and summer bacterioplankton from Antarctic Peninsula coastal surface waters. ISME J. 2012;6:1883-1900.

Xiong J, Zhu J, Dai W, Dong C, Qiu Q, Li C. Integrating gut microbiota immaturity and disease-discriminatory taxa to diagnose the initiation and severity of shrimp disease. Environ Microbiol. 2017;19:1490-1501.

Yoon J, Matsuo Y, Matsuda S, Adachi K, Kasai H, Yokota A. Rubritalea spongiae sp. nov. and Rubritalea tangerina sp. nov., two carotenoid- and squalene-producing marine bacteria of the family Verrucomicrobiaceae within the phylum 'Verrucomicrobia, isolated from marine animals. Int J Syst Evol Microbiol. 2007;57:2337-43.

Zhou Q, Chen T, Han S. Characteristics of bacterial communities in cyanobacteria-blooming aquaculture wastewater influenced by the phytoremediation with water hyacinth. Water. 2017;9:956. 